\title{
Geographic distribution of family physicians in Japan and the United States: a cross-sectional international comparative study
}

Yuji Okazaki ( $\square$ ur8nibhc1@gmail.com )

Akiota Hospital https://orcid.org/0000-0002-6310-0338

Shuhei Yoshida

"Hiroshima Daigaku"

Saori Kashima

"Hiroshima Daigaku"

Soichi Koike

Jichi Ika Daigaku

Masatoshi Matsumoto

"Hiroshima Daigaku"

\section{Research article}

Keywords: geographic distribution, family physicians, Japan, the United States

Posted Date: November 20th, 2020

DOI: https://doi.org/10.21203/rs.3.rs-61757/v2

License: (c) (i) This work is licensed under a Creative Commons Attribution 4.0 International License. Read Full License 


\section{Abstract}

Background: Family physicians are known to distribute more equally among the population than other physicians. The maturity of family medicine, i.e. the length of its history as a part of healthcare system and the population of qualified family medicine experts, may affect the distribution, but this has not been shown in the literature. This study compares the geographic distribution of family physicians in Japan and the United States (U.S.), both of which are developed countries without a physician allocation system by the public sector, but the two countries differ greatly in the maturity of family medicine as a clinical specialty.

Methods: This is a cross-sectional international comparative study using publicly available online database on the number of physicians in Japan (Boardcertification Database of Japan Primary Care Association, and Survey of Physicians, Dentists and Pharmacists by Ministry of Health, Labour and Welfare) and the U.S. (Area Resource File by Health Resources and Services Administration). The municipalities in Japan and counties in the U.S. were divided into quintile groups according to population density. The number of family physicians per unit population in each group of areas was calculated. The geographic distribution of all physicians in Japan was simulated assuming that the proportion of family physicians among all physicians in Japan (0.16\%) was increased to that in the U.S (11.8\%).

Results: The distribution of family physicians in Japan noticeably shifted to the areas with the lowest population density. In contrast, family physicians in the U.S. distributed equally across areas. The distribution of physicians with other specialties (general internists, pediatricians, surgeons and obstetricians/gynecologists) shifted heavily to the areas with highest population density in both countries. The simulation analysis showed the geographic maldistribution of all physicians improved substantially if the proportion of family physicians in Japan increases to that in the U.S.

Conclusion: The distribution of family physicians is more equal than other medical specialists, and the immaturity of family medicine can even lead to a ruralbiased distribution. In a country with emerging family medicine such as Japan, increasing the number of family physicians may effectively mitigate the urban-rural imbalance of physician supply.

\section{Background}

Geographic maldistribution of physicians is a serious social problem around the world [1, 2]. An increasing amount of evidence suggests that increasing the number of primary care specialists will help to improve the urban-rural gap of physician supply [3]. Compared with other medical specialists, primary care specialists or family physicians tend to have a more equitable distribution between urban and rural areas [4]. However, it is unclear whether this pattern of geographic distribution of family physicians is similar among different countries.

Countries with matured family medicine, or countries in which primary care is an established academic discipline, recognized as an important part of healthcare system, and is filled with sufficient number of certified family physicians, may have a different geographic distribution of family physicians from countries in which family medicine is still emerging. In a society with a mature specialty in family medicine, there is scant room for domain-specific specialists (such as gastroenterologists and dermatologists) to enter the primary care market because primary care is customarily and institutionally provided by family physicians. In such a country, family physicians can find a job at a place whether it is urban or rural. In contrast, in a society without a mature specialization in family medicine, there are already many domain-specific specialists in the primary care market, especially in urban areas. In such societies, specialoids (i.e. domain-specific specialists who provide primary care services without a qualification for primary care providers), have already established a solid position in the market as a primary care provider with occasional work as a specialist. Patients are accustomed to this specialist-led primary care environment and to choosing them according to their symptoms $[5,6]$. In such a country, new physicians who were board-certified in family medicine have difficulty in finding jobs in urban areas, and must work in rural areas where there is less competition with other specialists.

Traditionally, Japan did not have a board-certification system for primary care physicians. Domain-specific specialists, after finishing a career in a hospital, were, and still are, expected to provide primary care in a clinic as their second career. There was no formal retraining system for the ex-specialist primary care physicians. In 2009, the Japanese Primary Care Association (JPCA) started the board-certification system for family physicians who completed a three-year family medicine (katei-iryo) training program, and the number of the certified family physicians has increased gradually [7]. As a part of recent reform of specialty certification, the Japanese Medical Specialty Board (JMSB), the only formal and cross-discipline specialty board independent of each medical specialty body, referenced the content of JPCA family medicine training, and in 2021 started a new certification in general practice (sougou-shinryo) as one of the 19 basic specialty areas. The JMSB certification will take the place of the JPCA certification since 2021. This reform is expected to increase the number of family physicians/general practitioners dramatically. However, the history of family medicine in Japan is much shorter than that in other countries. The percentage of family physicians to all physicians is less than 1\% [7]. Japan is still excluded from the "generalist medical practitioners" data in the OECD Health Data due to the lack of generalist producing scheme until recently [8]. It can be said therefore that Japan is a society with immature family medicine, which is quite unusual for a developed country.

In the United States, in contrast, the field of family medicine is more mature. The professional body for family physicians, the American Academy of Family Physicians, was founded in 1947, and family medicine was recognized as a formal specialty in clinical medicine in 1969 . The U.S. already have many boardcertified family physicians. In $2017,12.6 \%$ of medical school graduates entered a family medicine training program, and over the last decade the number of the residents has increased [9]. Thus, in the U.S., family medicine is accepted as a part of healthcare system.

An international comparative study of the geographic distribution of family physicians is needed to reveal the relationship between the maturity of family medicine and the distribution of family physicians. Japan and the U.S. are suitable for such a comparison for two reasons. One reason is that there is a remarkable difference in the maturity of family medicine between the two countries, while both countries are developed countries in which area-based physician number data is available to the public. Also, in these two countries the geographic allocation of physicians is not regulated by the government as is

Page 2/10 
conducted in some European countries. The other reason is that in both countries a major part of healthcare system is privately operated and owned. Practice of physicians in both countries is a personal business, or an employment by a for-profit private or semi-private hospital. In such a society, unlike in societies whose healthcare system is dominated by publicly owned medical institutions, the distribution of physicians is driven largely by the market [10]. Thus, the distribution in both countries can be interpreted in the same dynamics, which is different from the government-led physician distribution in some European countries and Canada. Between Japan and the U.S. we can assess the relationship between the maturity of family medicine and the geographic distribution of family physicians excluding the impact of the intervention by the public sector on the distribution.

We thus evaluate the geographic distribution of family physicians and other major clinical specialists in Japan and the U.S., and compare them internationally. Family physicians should be distributed equally because family medicine improves health indicators for all community residents, and contributes to patient satisfaction and lower health care costs [11]. We also simulate the distribution of all physicians in Japan, assuming that the proportion of family physicians among all the physicians step-wisely increases to the level of that in the U.S. Based on the results, we will discuss the association between the maturity of family medicine and the geographic distribution of family physicians, and how important it is to increase the number of family physicians to reduce the urban-rural imbalance of physicians.

\section{Methods}

Study setting

This is a cross-sectional international comparative study using publicly available online database including all municipalities in Japan, counties and the District of Columbia in the U.S.

Definition of family medicine

This study defines family medicine as medical care provided by JPCA-certified family physicians (in Japan), and as medical care provided by American Board of Family Medicine-certified family physicians (in the U.S.).

Data of physicians in Japan

We collected an online database of JPCA-certified family physicians in 2018 who gave permission to the JPCA office to make their information available online [12]. The data disclosed each physician's name, workplace (municipality and medical institution) and area of special interest. The number of physicians in other specialties who worked as clinicians in a medical institution and were board-certified by the Japanese Society of Internal Medicine, Japan Pediatric Society, Japan Surgical Society, and Japan Society of Obstetrics and Gynecology was collected from the online database of the Survey of Physicians, Dentists and Pharmacists 2018 compiled by the Ministry of Health, Labour and Welfare [13].

Data on municipalities in Japan

Japan is divided into three administrative levels: national, prefectural and municipal. The number of municipalities (cities, towns and villages) was 1741, and we collected data on 1737. Population and population density in 2015 were collected for each municipality from online database of population census compiled by the Ministry of Internal Affairs and Communications [14]. We defined the rurality of each municipality by its population density. We calculated the population density of a municipality by dividing the population (number of residents) by land area (square kilometers). We divided the municipalities into quintiles (i.e. one-fifth of a set) according to population density so that the number of municipalities in each group was $20 \%$ of all the municipalities (Quintile $1<=43.4$, Quintile $2<=140.6$, Quintile $3<=403.9$, Quintile $4<=1650.4$, Quintile $5<=22380.2$ people per square kilometer). The municipality boundary data was obtained from the National Spatial Planning and Regional Policy Bureau of the Ministry of Land of Japan.

Data on physicians and counties in the U.S.

The number of physicians and population density in U.S. counties were collected from the Area Resource File published by Health Resources and Services Administration [15]. In the database, information on 3221 of the 3230 counties was available. Data on the number of physicians in 2017 was used for the analysis. The number of physicians was the sum of Doctor of Medicine (M.D.) and Doctor of Osteopathic Medicine (D.O.) who provided active patient care and were non-federal doctors. Data on the number of board-certified family physicians and that of other board-certified physicians (general internists, pediatricians, general surgeons, and obstetricians and gynecologists) was used for the analysis. Population information in 2018 and area information in 2010 for each county contained in the database was also used for the analysis. To evaluate rurality, as in Japan, counties were divided into quintiles according to population density (Quintile $1<=4.6$, Quintile $2<=11.9$, Quintile $3<=24.3$, Quintile $4<=67.4$, Quintile $5<=18721.1$ people per square kilometer). Census boundary data was obtained from the U.S. Census Bureau TIGER/Line Shapefiles.

\section{Simulation analysis}

We simulated the geographic distribution of all the physicians in Japan assuming that the proportion of family physicians among all the physicians in Japan increased stepwise to that in the U.S. This analysis was based on the following assumptions: 1) the number of family physicians increased and the number of the other physicians decreased, resulting in no change in the total number of physicians; 2 ) the distribution patterns of family physicians and the other physicians remained constant.

The proportion of family physicians in Japan was $0.16 \%$, while the proportion of family physicians in the U.S. was $11.8 \%$. To increase the proportion to the level of the U.S., the number of family physicians in Japan needed to increase by 72.6 times and the number of other specialists needed to decrease by 0.88 times, resulting in the total number of physicians holding steady. We multiplied family physicians and other physicians as such, while maintaining the

Page 3/10 
distribution of each group of physicians. We then calculated the total number of physicians per population in each group of population density quintile, and compared it before and after the simulation. We simulated three patterns of increase of family physicians: 10, 30 and 72.6 times the current level. The magnification of 10 times was derived from the assumption that the number of the entry to general practice (sougou-shinryo) training program triples (570) the current level (190) and this condition lasts for 20 years. Also, the 30 times assumes that the number increased by five times (950) and lasts for 20 years. The distribution of family physicians can be influenced by factors that change as the number of family physicians increases. For example, the size of the population accustomed to family physicians, the age distribution of family physicians, and the amount of money family physicians can save for starting their private practice could change as this number increases. To simplify the calculation, this simulation does not consider these factors.

Statistical analysis:

We used the chi-square test to compare the distribution of ordinal variables among five groups of areas in both countries. We used the residual analysis to compare the real value of the number of family physicians per unit population and the expected value derived from the distribution of all family physicians in both countries. All statistical analyses were performed using Microsoft Excel and STATA/SE version 15 (Stata Crop 2017). We excluded data of four (0.2\%) municipalities and nine $(0.3 \%)$ counties because of a lack of information about the number of physicians or population density. A p-value, 0.05 (two-sided test) was considered statistically significant.

\section{Results}

The national population in Japan was $127,094,745$ and that of the U.S. was $330,530,359$. There were 320,084 physicians in Japan and 899,244 in the U.S. There were 519 (77.2\%) family physicians in Japan and 105,999 (100\%) in the U.S.; this data was available in an online database. Fig. 1 shows the number of family physicians per unit population in each quintile of population density in Japan and in the U.S. The concentration of family physicians in Japan was relatively low in the densely populated coastal areas. In the less densely populated inland mountain areas, the concentration of family physicians was relatively high. In contrast, family physicians in the U.S. did not concentrate in certain geographic locations. These patterns of distribution also appear in Fig. 2 which depicts the number of family physicians per unit population in each quintile of population density. The distribution of family physicians in Japan shifted substantially to Quintile 1 (the lowest population density) municipalities (Fig. 2A). In contrast, family physicians were uniformly distributed across quintiles in the U.S. (Fig. 2B). Chi-square tests showed that the distribution of Japanese family physicians among the quintile groups differed significantly from that of American family physicians $(p<0.001)$. The residual analysis showed that the number of family physicians in Quintile 1 in Japan $(117$ per $10,000,000$ ) was significantly higher than the number expected from the distribution of all family physicians (the total of Japanese and U.S. family physicians) (73.5 per $10,000,000)(p<0.001)$. The number of family physicians in Quintile 5 in Japan $(31$ per $10,000,000)$ was significantly lower than the number expected from the distribution of all family physicians $(56.8$ per $10,000,000)(p<0.001)$. Fig. 3 shows the distribution of other specialists per 100,000 population classified by population density quintile in Japan and the U.S. The distribution of other specialists shifted markedly to urban areas in both Japan and the U.S., unlike that of family physicians.

In the simulation analysis, assuming an increase in the number of family physicians in Japan, the geographic maldistribution of all physicians in Japan would improve stepwise if the number of family physicians increased from its current level to 10, 30 and 72.6 times greater (Fig. 4). For example, the number of physicians in Quintile 1 increased by 1.64 times from 2558 to 4199 if the number of family physicians increased to the same level of the U.S. (72.6 times)

\section{Discussion}

The distribution of family physicians in Japan significantly shifted to rural areas compared with the distribution of family physicians in the U.S.; in both countries other specialists concentrated heavily in urban areas. If the proportion of family physicians in Japan increased to that in the U.S., the geographic maldistribution of all physicians improved substantially. These results have two implications. One implication is that the distribution of family physicians is roughly equitable among the population in any society compared with that of other specialists, but the distribution can be biased substantially to rural areas in a society in which family medicine is emerging. The second implication is that, based on the rural-biased distribution of family physicians in Japan, increasing the number of family physicians can resolve the urban-rural imbalance in the supply of physicians.

Family physicians distribute equally among population in most societies with a mature primary care system. One reason for the equal distribution is that family physicians can make the most of their expertise in the rural healthcare environment [16, 17]. In urban areas, there are many more medical facilities, including highly specialized ones, and the geographic accessibility to medical care is much higher than in rural areas [18]. This gives patients in urban areas more choices when it comes to their care. They can go to medical institutions that specialize in their health conditions [19]. In contrast, in rural areas, health care providers are required to provide holistic and comprehensive care [20]. The absence of nearby health care facilities also makes it easier for physicians to provide continuity of care to a single patient [16]. Therefore, family physicians can provide continuous and comprehensive services in rural areas, two of the core values of primary care [16, 21, 22]. In contrast, for other specialists, rural areas may not be an ideal place to apply their expertise. They need to treat a narrower spectrum of diseases, which is rare in rural areas, and thus need to cover a wider geographic area with a larger population to stay in business [23]. As a result, the distribution of other specialists tends to shift to urban areas [24].

In Japan however, the distribution of family physicians shifted to the rural areas. This can be linked to the immaturity of family medicine in Japan's healthcare system. In Japan only about 10 years have passed since family medicine was established as a clinical discipline with a board-certification system. Only $0.2 \%$ of all physicians in Japan are board-certified family physicians. Urban primary care providers were other specialists originally employed by a hospital, who then opened their own private clinics [5]. These former specialists treat some patients within their specialty, and also offer primary care services without being trained in primary care or certification as a family physician. It is difficult, if not impossible, for family physicians, all of whom were board- 
certified recently, to enter this specialoid-saturated market. Therefore, they might prefer to work in rural areas where competition with these specialoids is less fierce. In a society like Japan's, with immature family medicine, family physicians are at a disadvantage in the health professional market.

Japan's unique system of healthcare provision may also have affected the distribution of family physicians. Almost all physicians who have completed postgraduate clinical training are employed by a hospital as a domain-specific specialist early in their career. Even if these physicians, including younger family physicians, would prefer to work in a clinic, it is financially impossible for them to do so, because most clinics in Japan are private solo practices that require approximately US\$880,000 to establish [25]. Therefore, it is extremely difficult for younger family physicians to work in their own clinics. To continue practicing family medicine, a substantial proportion of them must be employed by a public clinic set up by the local government to provide medical care in Japan's rural, remote and underserved areas. These are, however, a small fraction of all clinics in Japan.

The simulation analysis showed that the geographic maldistribution of physicians in Japan improved with a larger number of family physicians. The geographic maldistribution of physicians has been a serious social problem in Japan [26]. To compensate for the shortage of doctors in rural areas, public medical institutions in the rural areas were established by the national and municipal governments. Jichi Medical University, established solely for the purpose of training rural physicians, was established in 1972, and a regional quota, a special admission quota for producing rural physicians, was spread among most of the medical schools in Japan for the last ten years $[27,28]$. Even with these ambitious national policies, the maldistribution of physicians has not changed. Instead, there is an even greater disparity in the supply of physicians between rural and urban areas [26, 29, 30]. The unique distribution of family physicians in Japan could contribute to ameliorating the maldistribution of physicians. Based on the results of this study, policies to increase the number of family physicians and general practitioners and reining in the number of other specialists is a plausible solution for national and local governments [31].

This study has several limitations. First, we could not obtain the data on all JPCA-certified family physicians because individual information of some of them was not available on the JPCA website. We considered, however, that selection bias for Japanese family physicians was minimal given the high (77.2\%) covering proportion. Second, the simulation analysis assumed the distribution of family physicians did not change when it actually increased dramatically. If the number of family physicians increased to such an extent, it is possible that their geographic distribution substantially changed because of changes in government incentives, savings, supply-demand balance, and recognition of family physicians among the population. This change would enable family physicians to replace specialoids in urban areas and leads to a total distribution of physicians different from that shown by the simulation. Above all it was not realistic that the number of family physicians in Japan increased by 72 times in a short period. The simulation was a thought experiment under an extreme assumption that showed, in a simple manner, the magnitude of the effect of the policy to increase the number of family physicians.

Two other important issues are the comparability of Japan and the U.S. and the limited generalizability based on the two-country comparison. The healthcare systems of Japan and the U.S. are quite different, especially in terms of their medical insurance systems. The results should therefore should be interpreted cautiously. Adding another country or two to the comparison would make the conclusion sounder. For example, the maturity of family medicine is even higher in the United Kingdom and the Netherlands than in the U.S; the percentages of general practitioners (GPs) among all doctors are $26.2 \%, 45.4 \%, 11.7 \%$, respectively [8]. These European countries have a system of population registration at each GP practice and seem to have a smaller disparity of the GP supply between urban and rural areas than Japan and the U.S. although there is still some difficulty in recruiting physicians to work in rural areas [24, 26, 32, 33, 34]. Adding these countries to the international comparison would reveal the effect of such a socialized system of primary care provision.

\section{Conclusion}

The distribution of family physicians is more equal than other medical specialists and can be affected by the maturity of family medicine of the society. In countries like Japan in which family medicine has emerged recently, the distribution can be biased to rural areas. In such countries, increasing the number of family physicians and controlling the number of other specialists may be a way to rectify the urban-rural imbalance of physicians.

\section{Abbreviations}

JPCA: The Japan Primary Care Association, U.S.: United States, JMSB: The Japanese Medical Specialty Board

\section{Declarations}

Ethics approval and consent to participate

This study needs no ethical approval because the data used for the analyses was all available online.

Consent for publication

Not applicable.

Availability of data and materials

Available online to anyone.

Competing interests

The authors declare that they have no competing interests. 
Funding

This study was supported by grant-in-aid from Japan Primary Care Association.

Authors' contributions

All authors contributed to the development of this manuscript. YO was responsible for study design, data collection, interpretation and writing of the draft. SY and SaK assisted with analysis and interpretation of data. MM supervised the whole study by contributing to the study design, data collection, interpretation of data and writing of the draft. SoK contributed to the interpretation of data and writing of the draft. All authors have read and approved the final version of this manuscripts.

Acknowledgements

Not applicable.

\section{References}

1. Makaroff LA, Green LA, Petterson SM, Bazemore AW. Trends in Physician Supply and Population Growth. Am Fam Physician. 2013;87(7). https://pubmed.ncbi.nlm.nih.gov/23547599/. Accessed 1 Jul 2020.

2. Ono T, Schoenstein M, Buchan J. Geographic Imbalances in Doctor Supply and Policy Responses. OECD Heal Work Pap. 2014(2);1-66. http://dx.doi.org/10.1787/5jz5sq5ls1wl-en. Accessed 1 Jul 2020.

3. Increasing access to health workers in remote and rural areas through improved retention. WHO. 2010;1-80. https://www.who.int/hrh/retention/guidelines/en/. Accessed 1 Jul 2020.

4. Fryer GE, Green LA, Dovey SM, Phillips Jr RI. The United States Relies on Family Physicians Unlike Any Other Specialty. American Family Physician. 2001;63(9):1669.

5. Ikegami, N., Campbell JC. The art of balance in health policy: Maintaining Japan's low-cost, egalitarian system. Chuko-shinsyo. 1996.

6. Hashimoto H, Ikegami N, Shibuya K, et al. Cost containment and quality of care in Japan: Is there a trade-off? The Lancet. 2011;378(9797):1174-82.

7. Kato D, Ryu H, Matsumoto T, Abe K, et al. Building primary care in Japan: Literature review. J Gen Fam Med. 2019;20(5):170-9.

8. Health Care Resources: Physicians by categories. OECD. https://stats.oecd.org/Index.aspx?Queryld=30173. Accessed 1 Jul 2020.

9. Phillips JP, Wendling AL, Bentley A, Marsee R, Morley CP. Trends in US medical school contributions to the family physician workforce: 2018 update from the American Academy of Family Physicians. Fam Med. 2019;51(3):241-50.

10. Brown MC. Do physicians locate as spatial competition models predict? Evidence from Alberta. CMAJ 1993;148(8):1301-7.

11. Starfield B. Is primary care essential? Lancet. 1994;344(8930):1129-33.

12. Japan Primary Care Association. Certified system. http://www.primary-care.or.jp/nintei_fp/fp_list.html. Accessed 25 Jan 2018.

13. The Survey of Physicians, Dentists and Pharmacists 2018 compiled by the Ministry ofHealth, Labour and Welfare. https://www.e-stat.go.jp/statsearch/files?

page $=1 \&$ layout $=$ datalist\&toukei $=00450026 \&$ tstat $=000001135683 \&$ cycle $=7 \&$ tclass $1=000001135684 \&$ tclass $2=000001135687 \&$ stat_infid $=000031889170$. Accessed 15 Jul 2020

14. Population census 2015 compiled by the Ministry of Internal Affairs and Communications. https://www.e-stat.go.jp/stat-search/files? page $=1$ \&layout $=$ datalist\&toukei $=00200521 \&$ tstat $=000001080615 \&$ cycle $=0 \&$ tclass $1=000001089055 \&$ tclass $2=000001089056 \&$ stat_infid $=000031473210$. Accessed 15 Jul 2020.

15. Health Resources \& Services Adminstration. https://data.hrsa.gov/data/download. Accessed 15 Jul 2020.

16. Medicine I of. A Manpower Policy for Primary Health Care: Report of a study. Washington, DC: The National Academies Press; 1978.

17. Ricketts, Thomas C. Rural Health in the United States. Oxford University Press, U.S.A. 1995;41.

18. Rabinowitz HK, Paynter NP. The rural vs urban practice decision. J Am Med Assoc. 2002;287(1):113

19. Kaneko M, Motomura K, Mori H, et al. Gatekeeping function of primary care physicians under Japan's free-access system: A prospective open cohort study involving 14 isolated islands. Fam Pract. 2019;36(4):452-9.

20. Hutten-Czapski P, Pitoblad R, Slade S. Short Report: Scope of Family Practice in Rural and Urban Settings. Can Fam Physician. 2004;50:1548-50.

21. Weigel PAM, Ullrich F, Shane DM, Mueller KJ. Variation in Primary Care Service Patterns by Rural-Urban Location. J Rural Heal. 2016;32(2):196-203.

22. Medicine I of. Primary Care: American's Health in a New Era. Donaldson MS, Yordy KD, Lohr KN, Vanselow NA, editors. Washington, DC: The National Academies Press; 1996.

23. Australian Medical Workforce Advisory Committee (AMWAC). Sustainable specialist services: a compendium of requirements, 2004 update, AMWAC Report 2004.4. North Sydney. 2004. https://www1.health.gov.au/internet/publications/publishing.nsf/Content/work-res-ruraud-toc work-res-ruraudlis work-res-ruraud-lis-b work-res-ruraud-lis-b-4. Accessed 15 Jul 2020.

24. Matsumoto M, Inoue K, Farmer J, Inada H, Kajii E. Geographic distribution of primary care physicians in Japan and Britain. Heal Place. 2010;16(1):164-6. 
25. Clinic Keiei Kenkyukai (Clinic Management Research Group). linkaigyou Handbook of opening private practice. Nihon Iryou Kikaku: Tokyo; 2005 (in Japanese).

26. Matsumoto M, Inoue K, Bowman R, et al. Geographical distributions of physicians in Japan and US: Impact of healthcare system on physician dispersal pattern. Health Policy (New York). 2010;96(3):255-61.

27. Matsumoto M, Inoue K, Kajii E, Takeuchi K. Retention of physicians in rural Japan: concerted efforts of the government, prefectures, municipalities and medical schools. 2010;10(2):1432.

28. Matsumoto M, Takeuchi K, Owaki T, et al. Results of physician licence examination and scholarship contract compliance by the graduates of regional quotas in Japanese medical schools: A nationwide cross-sectional survey. BMJ Open. 2017;7(12):e019418.

29. Kobayashi Y, Takaki H. Geographic distribution of physicians in Japan. Lancet. 1992;340(8832):1391-3.

30. Toyabe SI. Trend in geographic distribution of physicians in Japan. Int J Equity Health. 2009;8(1):1-8.

31. Matsumoto M, Takeuchi K, Yokobayashi K, Tazuma S. Geographic Maldistribution of Physicians in Japan : Increasing the Number of Generalists is One Solution. J Gen Fam Med. 2015;16(4):260-4.

32. Blane DN, McLean G, Watt G. Distribution of GPs in Scotland by age, gender and deprivation. Scott Med J. 2015;60(4):214-9.

33. Capaciteitsorgaan, Regionale spreiding Nederland van medisch specialisten [Regional distribution the Netherlands of medical specialists]. 2017, Utrecht: Capaciteitsorgaan.

34. NHS England : Targeted Enhanced Recruitment Scheme. https://www.england.nhs.uk/gp/the-best-place-to-work/starting-your-career/recruitment/. Accessed 31 Oct 2020

\section{Figures}
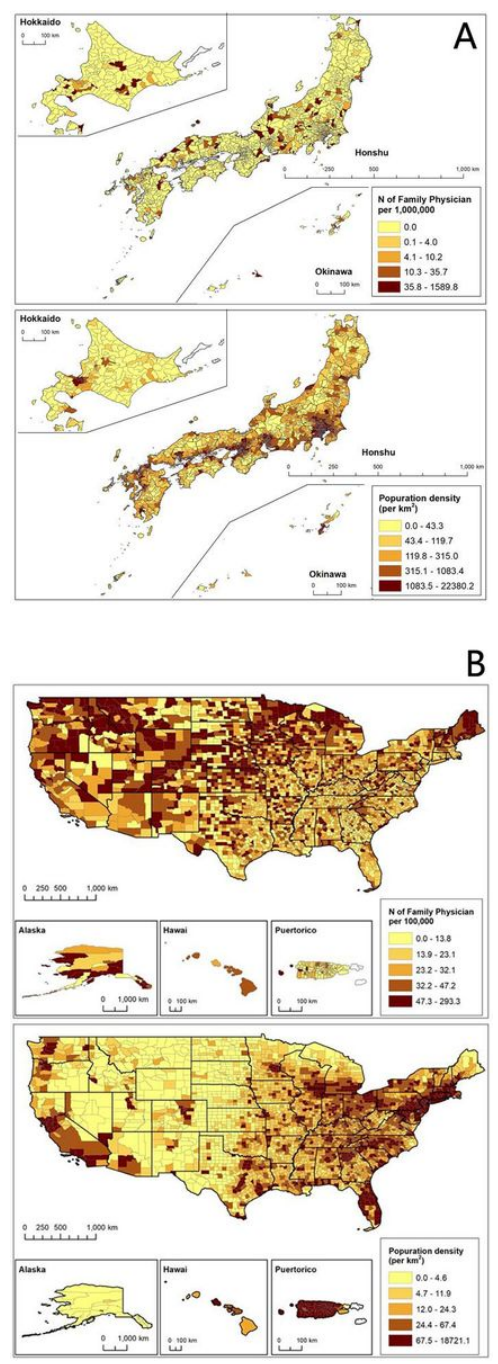

\section{Figure 1}

(A) Japan The upper map shows the number of family physicians per 1,000,000 population in each municipality. The lower map shows the population density in each municipality. The municipality boundary data was obtained from the National Spatial Planning and Regional Policy Bureau of the Ministry of 
Land of Japan. (B) United States The upper map shows the number of family physicians per 100,000 population in each county. The lower map shows the population density in each county. Census boundary data was obtained from the U.S. Census Bureau TIGER/Line Shapefiles.

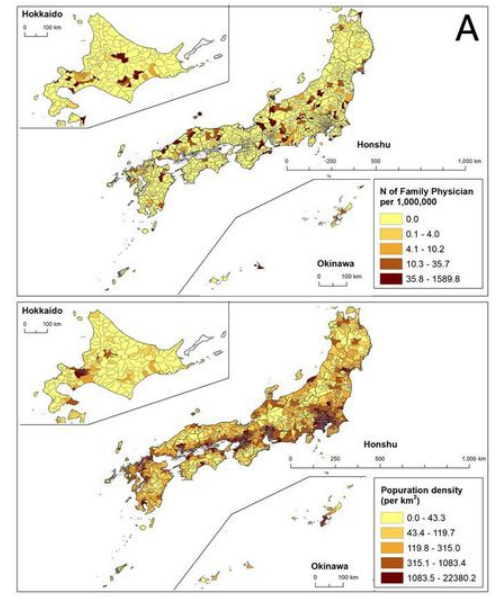

B

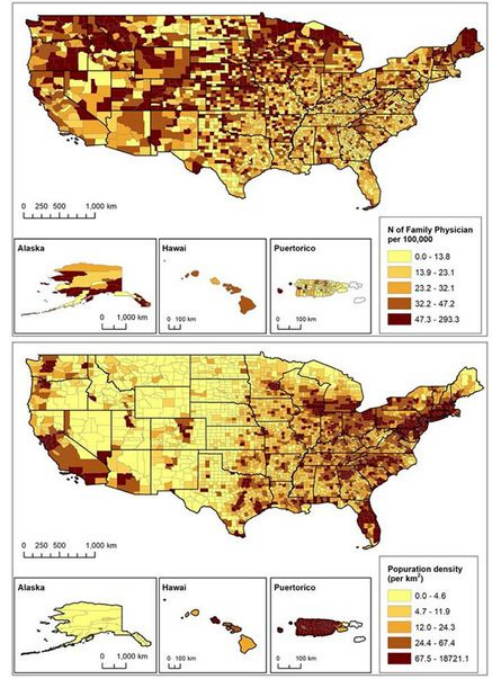

\section{Figure 1}

(A) Japan The upper map shows the number of family physicians per 1,000,000 population in each municipality. The lower map shows the population density in each municipality. The municipality boundary data was obtained from the National Spatial Planning and Regional Policy Bureau of the Ministry of Land of Japan. (B) United States The upper map shows the number of family physicians per 100,000 population in each county. The lower map shows the population density in each county. Census boundary data was obtained from the U.S. Census Bureau TIGER/Line Shapefiles.
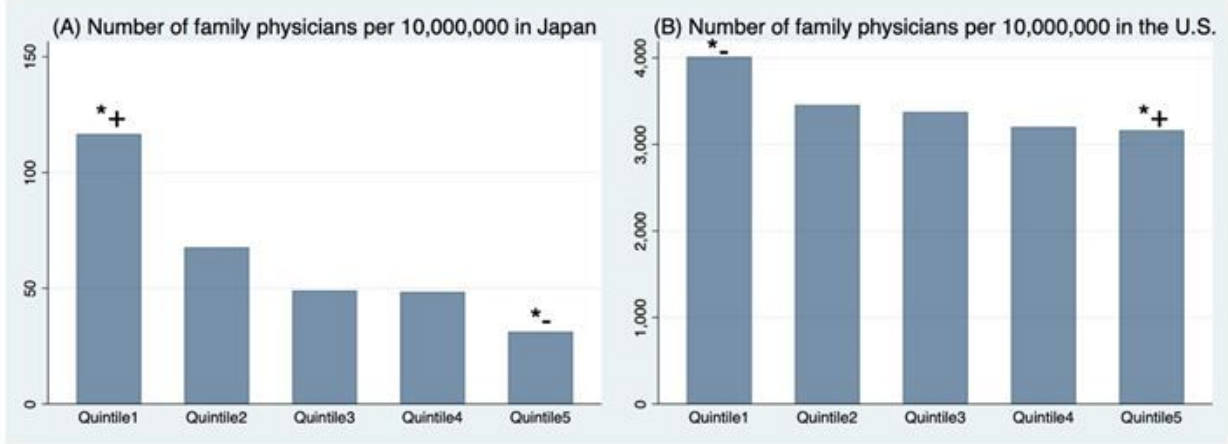

\section{Figure 2}

Number of family physicians per $10,000,000$ population in each quintile group of municipalities/counties sorted according to population density. Japan: Quintile $1<=46.4$, Quintile $2<=140.6$, Quintile $3<=403.9$, Quintile $4<=1650.4$, Quintile $5<=22380.2$ people per square kilometer US: Quintile $1<=4.6$, Quintile $2<=11.9$, Quintile $3<=24.3$, Quintile $4<=67.4$, Quintile $5<=18721.1$ people per square kilometer Residual analysis based on chi-square test which examines the difference between the real and expected value at each cell. *+: greater than expected. $\mathrm{P}<0.001{ }^{*}-$ less than expected. $\mathrm{P}<0.001$ 

8.

(A) Number of family physicians per $10,000,000$ in Japan
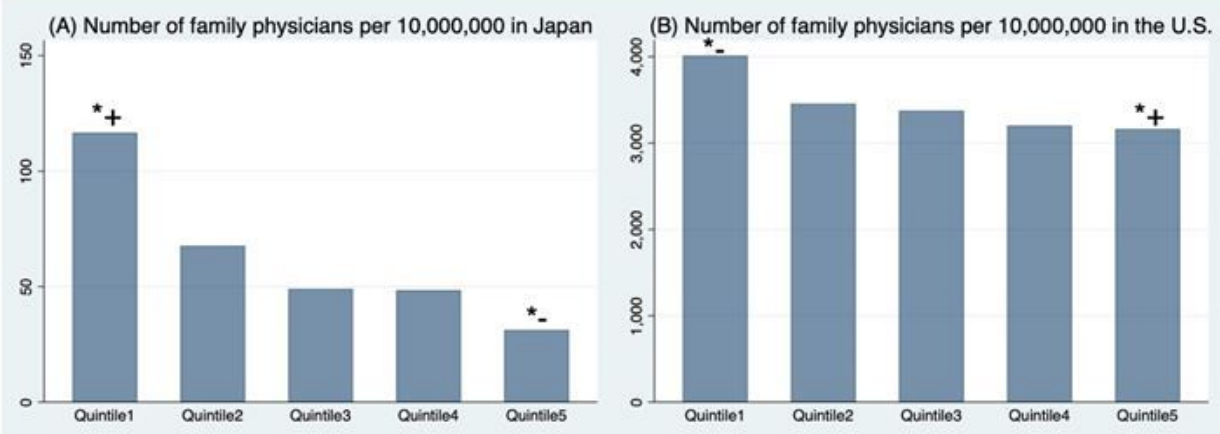

\section{Figure 2}

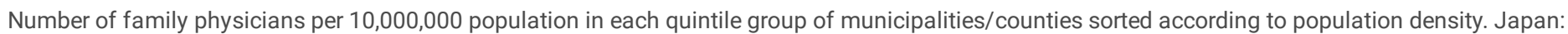

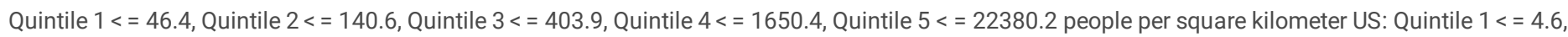

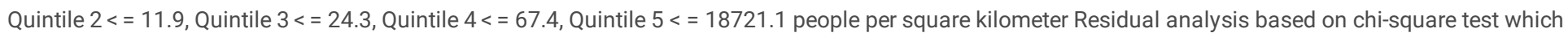
examines the difference between the real and expected value at each cell. *+: greater than expected. P<0.001 *-: less than expected. P<0.001

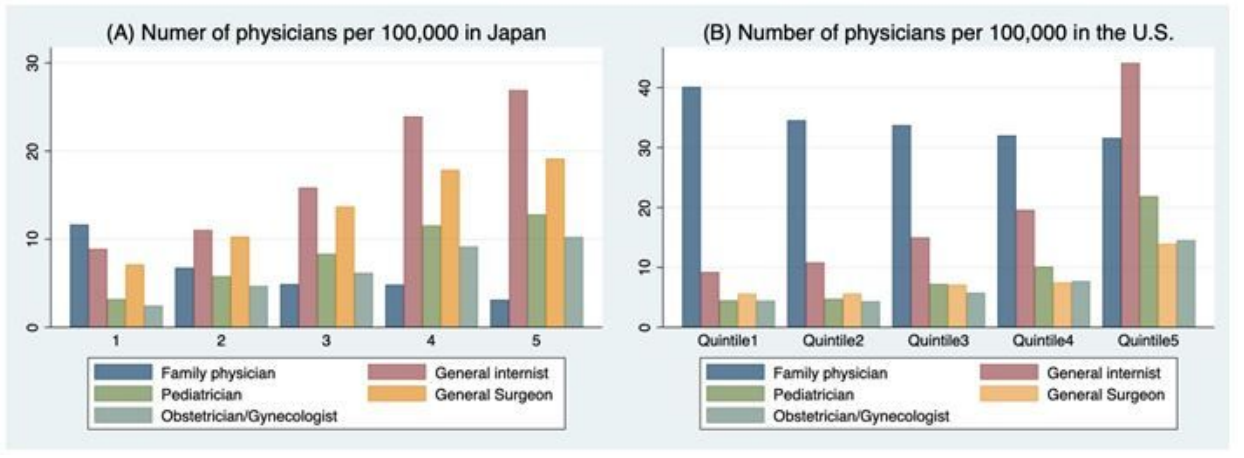

\section{Figure 3}

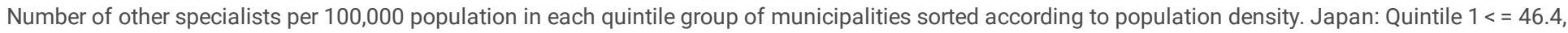

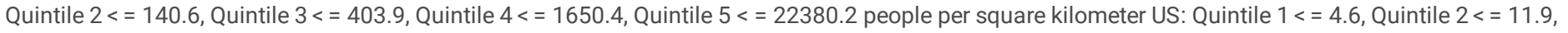

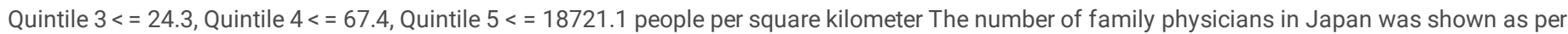
$1,000,000$.

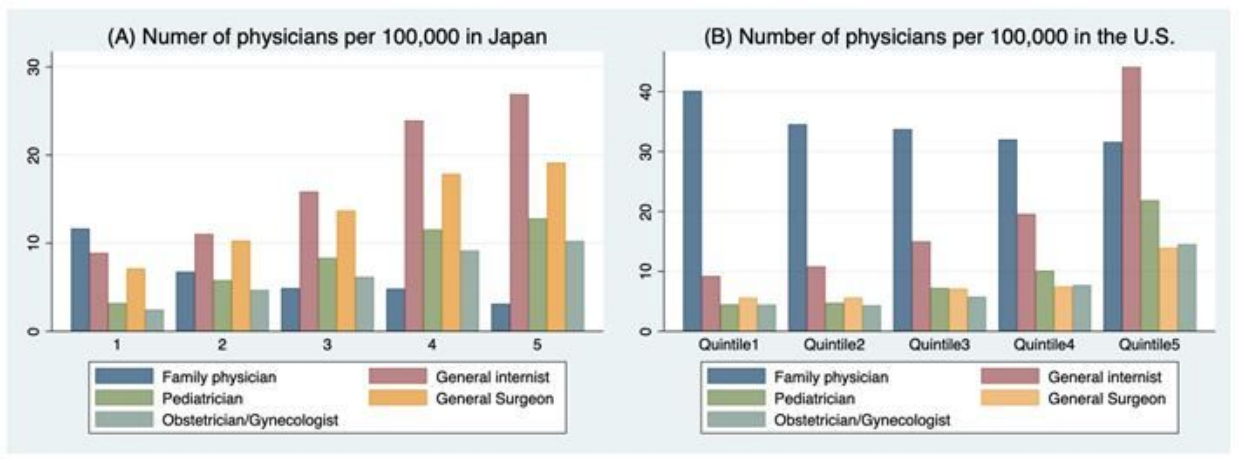

Figure 3

Number of other specialists per 100,000 population in each quintile group of municipalities sorted according to population density. Japan: Quintile $1<=46.4$, Quintile 2<= 140.6, Quintile 3<= 403.9, Quintile 4<= 1650.4, Quintile $5<=22380.2$ people per square kilometer US: Quintile 1<=4.6, Quintile $2<=11.9$, Quintile $3<=24.3$, Quintile $4<=67.4$, Quintile $5<=18721.1$ people per square kilometer The number of family physicians in Japan was shown as per $1,000,000$. 


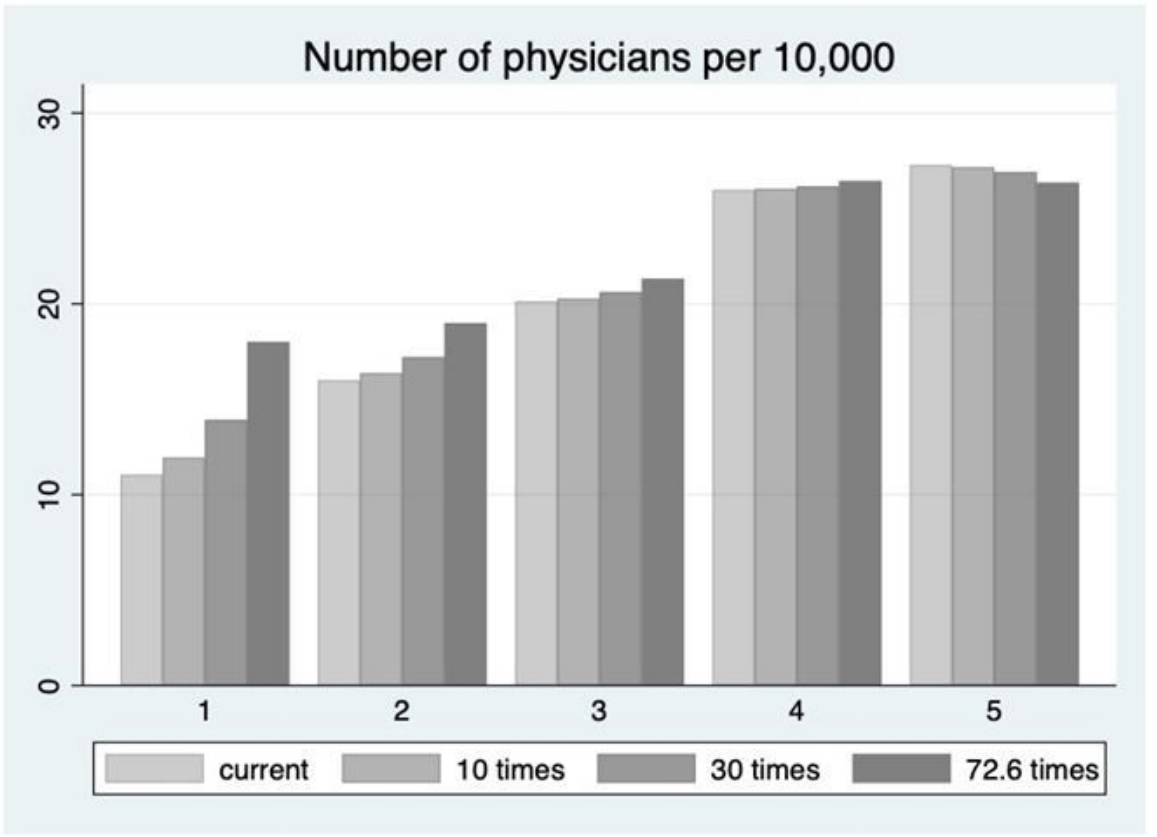

\section{Figure 4}

Simulated number of all Japanese physicians per 10,000 population in each quintile group of municipalities sorted according to population density. Japan: Quintile $1<=46.4$, Quintile $2<=140.6$, Quintile $3<=403.9$, Quintile $4<=1650.4$, Quintile $5<=22380.2$ people per square kilometer In the simulation, the proportion of family physicians among all physicians in Japan increased stepwise to the level of the U.S. (72.6 times), while the original distributions of the family physicians and that of other physicians were maintained.

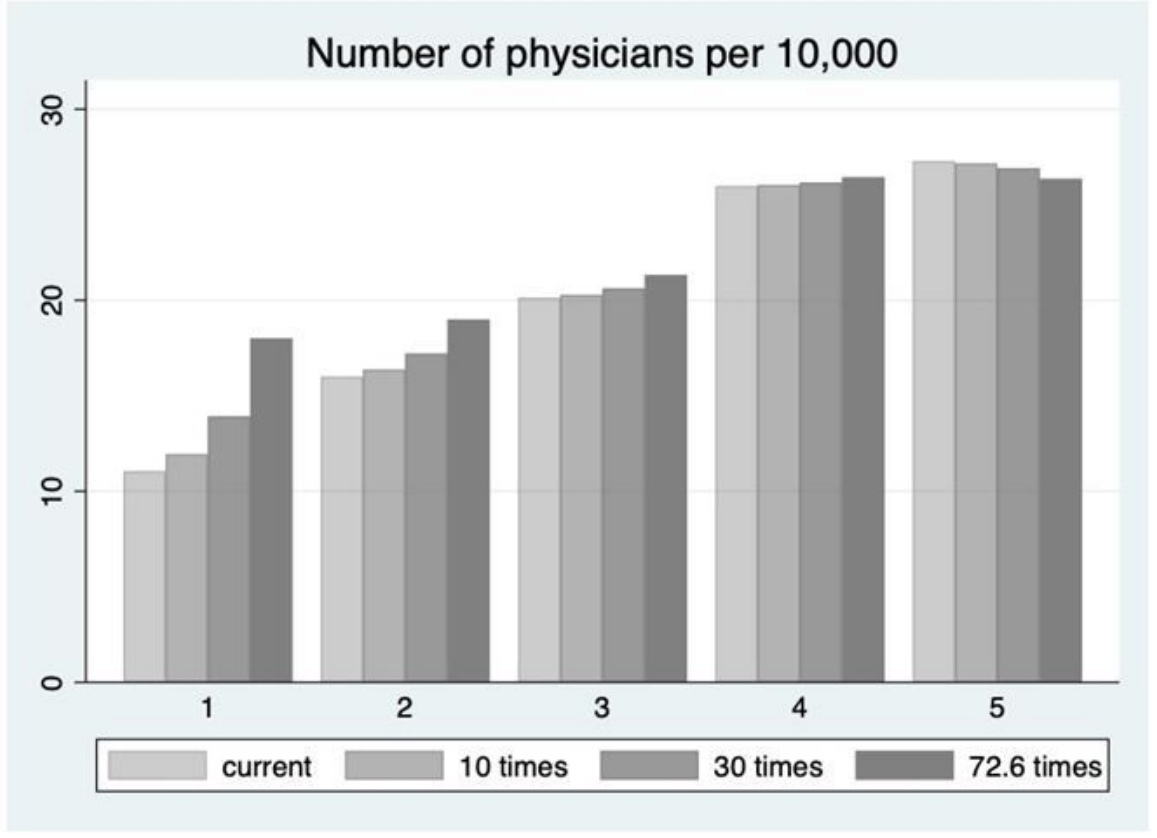

\section{Figure 4}

Simulated number of all Japanese physicians per 10,000 population in each quintile group of municipalities sorted according to population density. Japan: Quintile $1<=46.4$, Quintile $2<=140.6$, Quintile $3<=403.9$, Quintile $4<=1650.4$, Quintile $5<=22380.2$ people per square kilometer In the simulation, the proportion of family physicians among all physicians in Japan increased stepwise to the level of the U.S. (72.6 times), while the original distributions of the family physicians and that of other physicians were maintained. 